Analytica Chimica Acta, 83 (1976) 39-47

( Elsevier Scientific Publishing Company, Amsterdam - Printed in The Netherlands

\title{
THE COULOMETRIC TITRATION OF ACIDS AND BASES IN DIMETHYLSULFOXIDE MEDIA
}

\author{
M. BOS, S. T. IJPMA and E. A. M. F. DAHMEN \\ Department of Chemical Technology, Twente University of Technology, Enschede \\ (The Netherlands)
}

(Received 4th December 1975)

\section{SUMMARY}

The coulometric titration of $20-200 \mu \mathrm{eq}$ of acids and bases in DNISO media is described. In the titration of bases, the electro-oxidation of hydrogen at a platinized platinum electrode is used as the source of protons. The conditions for $100 \%$ current efficiency at this electrode are low current density to avoid passivity and regular treatment of the electrode with potassium dichromate-sulfuric acid to remove a poisoning sulfide layer. The accuracy of the titrations is better than $\pm 1 \%$. Very weak acids like phenols $\left(\mathrm{p} K_{\mathrm{a}}(\mathrm{DMSO}) \approx 16\right)$ can be titrated successfully. Tris(hydroxymethyl)aminomethane is the weakest base titrated.

Dimethylsulfoxide (DMSO) has been in use as a solvent for acid-base titrations since the early investigation of Kolthoff and Reddy [1]. Among the substances that have been titrated successfully in DMSO are phenols and benzoic acids [2], very weak acids and alcohols [3], weak bases and salts of weak acids [4] and strong acids [5].

This investigation was made to extend the field of nonaqueous coulometric titrations by combining the well known advantages of coulometric titrations with the particular properties of DMSO which make it such a suitable solvent for acid-base titrations.

In order to use the full acid-base range of a solvent, it is necessary that strong acid or base be generated from compounds without acid-base properties, and preferably from the solvent itself. In many cases, however, the current efficiency for the electrogeneration of acid or base from the solvent itself is less than $100 \%$; only the application of compounds that on electrooxidation or reduction produce a strong acid or a strong base with $100 \%$ current efficiency can then give the desired result. An example of a suitable compound is hydroquinone, from which $\mathrm{H}^{+}$-ions can be generated with $100 \%$ current efficiency in various organic solvents [6]. However, hydroquinone shows some acidic properties and thus decreases the acidbase range that can be used in titrations.

A more logical choice would be to utilize the electrochemical oxidation 
of hydrogen as the supply of hydrogen ions. The direct generation of acid in DMSO with a platinum working electrode and tetraethylammonium perchlorate as supporting electrolyte does not proceed with $100 \%$ current efficiency. Moreover, some bases to be titrated, e.g. 1,3-diphenylguanidine, are oxidized themselves under these conditions. Hence the electrochemical hydrogen oxidation in DMSO was tested for its usefulness in the coulometric titration of bases in this solvent.

\section{EXPERIMENTAL}

\section{Chemicals}

Dimethylsulfoxide (Merck, "Zur Synthese") was purified by heating it to $60-70^{\circ} \mathrm{C}$ under stirring in contact with potassium permanganate and barium oxide for $1 \mathrm{~h}$, while nitrogen was bubbled through the solution. After filtration, the DMSO was kept for $24 \mathrm{~h}$ over activated molecular sieve (3A, Union Carbide). Further purification was by vacuum distillation at $42^{\circ} \mathrm{C}$ and $3 \mathrm{~mm} \mathrm{Hg}$; a fraction of $80 \%$ was retained. After another 24-h storage over molecular sieve, the vacuum distillation was repeated. The water content of the final product was less than $0.01 \%$ (Karl-Fischer titration). No acid or base could be detected titrimetrically in this final product.

Tetraethylammonium perchlorate, tetrabutylammonium perchlorate, tetrabutylammonium nitrate, 2,4-dinitrobenzenesulfonic acid (all Eastman Kodak) and 2,4-dinitrophenol (Merck, reagent grade) were recrystallized from ethanol-ether and dried in vacuo at $40^{\circ} \mathrm{C}$. 2-Nitrophenol (Merck, reagent grade), $m$-cresol (Baker, PCS reagent), salicylic acid (ACF) and perchloric acid (Fluka, puriss. p.a., $70 \%$ ) were used as received. Great care should be exercised in preparing perchloric acid solutions in DMSO from the $70 \%$ product; very small additions of the perchloric acid and cooling the DMSO are mandatory to prevent explosions. Benzoic acid (UCB, reagent

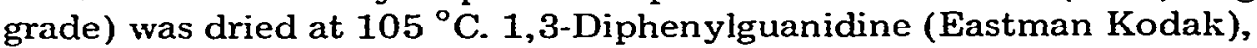
tris(hydroxymethyl)-aminomethane (Fluka, puriss. p.a.) and piperazine hexahydrate (Fluka, purum) were used as received. 1,1,3,3-Tetramethylguanidine (Eastman Kodak) was vacuum-distilled before use and transferred under nitrogen.

\section{Procedures}

The equipment used in the coulometric titrations has been described earlier [7] $\mathrm{pH}$ values were measured with an Ingold glass electrode (type HA 205) in combination with a silver/silver chloride electrode in saturated tetramethylammonium chloride in DMSO. This reference electrode was connceted to the titration vessel via a $0.2 \mathrm{M}$ TEAP/DMSO salt-bridge. When not in use the glass electrode was stored in aqueous buffer $\mathrm{pH} 4$. In the coulometric titrations of bases where hydrogen was used as the proton donor, hydrogen gas was bubbled through the solution starting 10 min before the actual titration. A platinized platinum gauze $\left(4 \mathrm{~cm}^{2}\right)$ was used as a working electrode for these titrations. 
Normally the samples were titrated with a current of $3 \mathrm{~mA}$ to a preset end-point. In the vicinity of the end-point the current was switched on intermittently. The end-point was previously determined from the recording of a titration curve of the sample. Up to four samples could be titrated in the same cell filling. $m$-Cresol and 2-nitrophenol could not be titrated in this way, because of a shift of the end-point after each new addition of sample. For these samples, the titration curves were recorded automatically. All samples were standardized titrimetrically with a relative accuracy of $\pm 0.2 \%$.

The voltammetric studies were performed with the use of a potentiostat (Tacussel, type BIPAD), a rotating platinum ring-disk electrode assembly (Tacussel) and a conventional $\mathrm{H}$-type cell. Before use the platinum electrode was immersed for $2 \mathrm{~min}$ in a potassium dichromate-sulfuric acid mixture, rinsed 3 times with double-distilled water and dried with a soft tissue. Current-voltage curves for the coulometric cell were also recorded with the use of the Tacussel BIPAD potentiostat.

\section{RESULTS}

\section{Titration of bases}

The direct coulometric titration of the bases 1,3-diphenyiguanidine and 1,1,3,3-tetramethylguanidine in DMSO showed current efficiencies ranging from 103 to $105 \%$. Colour changes which occurred during these titrations indicated that these bases are involved in the electro-oxidation at the working electrode as no similar darkening of the solution was observed when anodic oxidation of the solvent-supporting electrolyte mixture was carried out. Generation of acid in the solvent plus the supporting electrolyte was possible only at current efficiencies of 93-97\%. Table 1 shows the effect of the addition of different compounds to the DMSO-tetraethylammonium perchlorate (TEAP) mixture. As can be seen, 1.0 M water and $0.2 \mathrm{M}$ hydroquinone give satisfactory results with regard to current efficiency.

\section{TABLE 1}

Current efficiency for the generation of acid in DMSO- $0.2 \mathrm{M}$ TEAP with various substances added

\begin{tabular}{llll}
\hline $\begin{array}{l}\text { Substance } \\
\text { added }\end{array}$ & $\begin{array}{l}\text { Concn. } \\
\left(\mathrm{mol} \mathrm{I}^{-1}\right)\end{array}$ & $\begin{array}{l}\text { Current } \\
(\mathrm{mA})\end{array}$ & $\begin{array}{l}\text { Current } \\
\text { effic. (\%) }\end{array}$ \\
\hline- & - & 10 & $93-97$ \\
$\overline{\mathrm{H}_{2} \mathrm{O}}$ & - & 3 & $95-97$ \\
$\mathrm{H}_{2} \mathrm{O}$ & 0.1 & 10 & 97 \\
EtOH & 1.0 & 10 & 99.7 \\
Hydroquinone & 1.0 & 10 & 93.5 \\
Hydroquinone & 0.2 & 10 & 99.1 \\
$t$-BuOH & 0.2 & 3 & 99.8 \\
Hydrogen & 1.0 & 10 & 95 \\
\hline
\end{tabular}


However, internal generation of acid from $0.2 \mathrm{M}$ hydroquinone in DMSO-0.2 M TEAP for the titration of samples of tetramethylguanidine and diphenylguanidine still resulted in current efficiencies above $100 \%$ (101-103\%). Voltammetric experiments showed that these bases are oxidized at less positive potentials than hydroquinone. Thus participation of the bases in the electro-oxidation process is the most likely explanation of these high current efficiencies. External generation of the acid could be used to solve this problem, but is rather complicated experimentally. Instead the electro-oxidation of hydrogen in DMSO was studied to establish conditions for $100 \%$ current efficiency for this reaction.

The voltammetric curve for the oxidation at a rotating bright platinum disk, of hydrogen as a saturated solution in DMSO- $0.2 \mathrm{M}$ TEAP is given in Fig. 1. A passivity region can be observed at potentials above $+0.6 \mathrm{~V}$. Reproducible voltammetric curves can be obtained only when the scan is started from the anodic side $(+2.0 \mathrm{~V})$. If the electrode is kept for some time at potentials lower than $+0.6 \mathrm{~V}$ it becomes poisoned, most probably because of the formation of a film of dimethylsulfide on the electrode [8]. This is indicated by a lowering of the limiting current and a rounding of the steep drop to the passivity region.

The film can be removed from the electrode surface by treatment with potassium dichromate-sulfuric acid or by electrochemical oxidation of the film at potentials above $+1.8 \mathrm{~V}$. If the electrode surface is kept clean, there is a good proportionality between the height of the plateau in the voltammetric curves and the square root of the rotating speed (see Table 2). This implies that the limiting current is determined by the transport of hydrogen from the bulk of the solution to the electrode.

From the voltammetric curves at the various rotating speeds, the Tafel slope for the oxidation of hydrogen in DMSO was determined to be (116 \pm 2$) \mathrm{mV}$.

In the passivity region of the hydrogen oxidation, the oxidation of

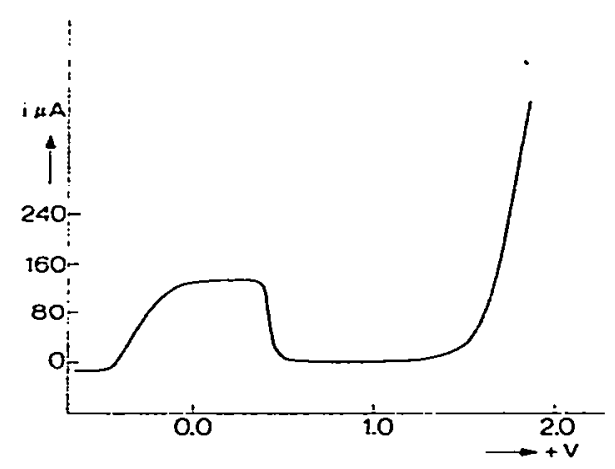

Fig. 1. Voltammetric curve for $\mathrm{H}_{2}$ oxidation in DMSO-0.2 $\mathrm{M}$ TEAP at the rotating disk electrode $\left(\omega=251.2 \mathrm{rad} \mathrm{s}{ }^{-1} ;\right.$ area $\left.=8 \mathrm{~mm}^{2}\right) . V$ vs. Ag/AgCl-0.1 M TMACl. 
TABLE 2

Limiting current for oxidation of hydrogen in DMSO-0.2 M TEAP at the rotating platinum disk electrode for various rotating spceds $(\omega)$ (Disk area $=8 \mathrm{~mm}^{2}$.)

\begin{tabular}{lll}
\hline $\begin{array}{l}\text { Rotating speed } \\
\text { (r.p.m.) }\end{array}$ & $\begin{array}{l}\text { Limiting current } \\
(\mu \mathrm{A})\end{array}$ & $\begin{array}{l}i_{\mathrm{d}} \omega^{-\frac{1}{2}} \\
\left(\mu \mathrm{A} \mathrm{rad} \text { rad }^{-\frac{1}{2}} \mathrm{~S}^{\frac{1}{2}}\right)\end{array}$ \\
\hline 2400 & 280 & 17.6 \\
2400 & 283 & 17.8 \\
1200 & 190 & 16.9 \\
600 & 136 & 17.2 \\
\hline
\end{tabular}

hydroquinone can take place unhindered, as can be seen from Fig. 2. When the potential of the platinum electrode is kept for several hours at a value in the passivity region, a subsequent scan towards more negative potentials produces a voltammetric curve similar to the one obtained during a continuous scan.

If tetrabutylammonium nitrate is used as the supporting electrolyte, the passivity region extends from less positive voltages (see Fig. 3). With tetrabutylammonium perchlorate as supporting electrolyte, the voltammetric curve shows the same characteristics as for tetraethylammonium perchlorate.

Table 3 shows the regions of electrochemical oxidation of hydrogen at metals other than platinum. These materials were tested in attempts to find a method for the electrochemical oxidation of hydrogen which would be unhindered by passivity. Palladium seems to be the best choice. However, there is a large overshoot in the titration of bases when acid is generated from $\mathrm{H}_{2}-$ DMSO-0.2 M TEAP at a palladium working electrode; this is probably due to slow diffusion of hydrogen ions from the interior of the palladium to the bulk solution.

The results of the study of the mechanism of the hydrogen oxidation at a

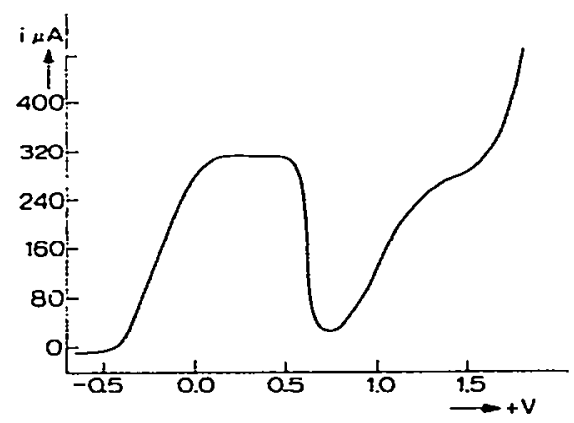

Fig. 2. Oxidation of hydroquinone and hydrogen in DMSO-0.2 M TEAP. Bright platinum rotating disk (area $=8 \mathrm{~mm}^{2}, \omega=251.2 \mathrm{rad} \mathrm{s}^{-1}$ ). 


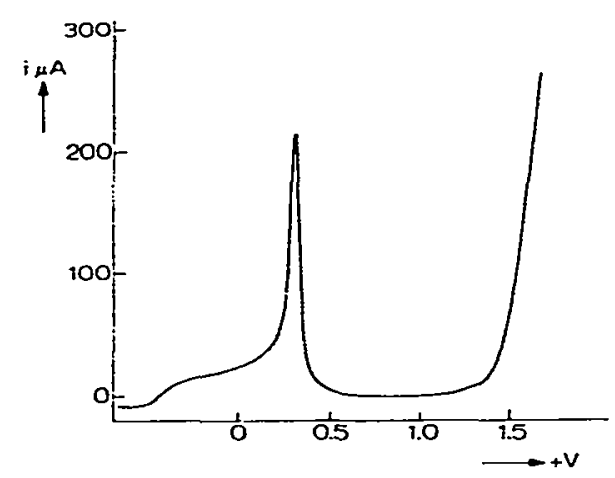

Fig. 3. Oxidation of hydrogen in DMSO-0.2 M TBAN on bright platinum rotating disk (area $=8 \mathrm{~mm}^{2}, \omega=251.2 \mathrm{rad} \mathrm{s}^{-1}$ ).

TABLE 3

Electrochemical oxidation of hydrogen in DMSO-0.2 M TEAP at various metal surfaces

\begin{tabular}{ll}
\hline Electrode material & $\begin{array}{l}\text { Region of } \mathrm{H}_{2} \text { oxidation } \\
\text { ( } V \text { vs. Ag/AgCl/TMACI-DMSO) }\end{array}$ \\
\hline Bright platinum & -0.5 to +0.6 \\
Gold & 1.0 to 1.2 \\
Nickel & - \\
Stainless steel & - \\
Palladium & -0.3 to $+1.8^{\mathrm{a}}$ \\
\hline
\end{tabular}

a No real passivation is observed, although there is a decrease in current at potentials higher than $\div 0.7 \mathrm{~V}$.

platinum electrode in DMSO indicate that it is possible to obtain $100 \%$ current efficiency for this reaction. For this it is necessary to platinize the electrode to increase the reaction rate and to use low current densities to avoid the passivity region. Moreover, the electrode surface must be cleaned regularly to remove any dimethylsulfide.

The electrochemical oxidation of hydrogen in DMSO $-0.2 \mathrm{M}$ TEAP was used under these conditions for the internal generation of acid to titrate various samples of bases. The results are summarized in Table 4 . An example of an automatically recorded titration curve is given in Fig. 4.

\section{Titration of acids}

Direct internal generation of bases at a bright platinum wire as working electrode in DMSO-0.2 M TEAP gave current efficiencies well below $100 \%$. During the process hydrogen gas is formed at the working electrode.

Addition of $0.1 \mathrm{M} \mathrm{m}$-cresol to the medium resulted in $100 \%$ current efficiency for the generation of base in this system. The overall reaction at the working electrode is probably 
TABLE 4

Coulometric titration of bases in DMSO-0.2 M TEAP-hydrogen with a platinized platinum gauze electrode $\left(4 \mathrm{~cm}^{2}\right)$ and a current of $3 \mathrm{~mA}$

\begin{tabular}{lccc}
\hline Compound & $\begin{array}{c}\text { Current } \\
\text { effic. }(\%)\end{array}$ & $\begin{array}{l}\text { No. of } \\
\text { detns. }\end{array}$ & $\begin{array}{l}s \\
\text { (\%) }\end{array}$ \\
\hline 1,3-Diphenylguanidine & 99.9 & 11 & 0.4 \\
Sodium benzoate $^{\mathrm{a}}$ & 100.8 & 6 & 1.5 \\
Piperazine $^{\mathrm{b}}$ & 99.8 & 7 & 0.4 \\
Tris(hydroxymethyl)aminomethane $^{\text {1,1,3,3-Tetramethylguanidine }}$ & 99.9 & 7 & 0.7 \\
1,1,3 & 99.4 & 6 & 0.4
\end{tabular}

a Dissolves during titration. 'Titration to the second end-point.

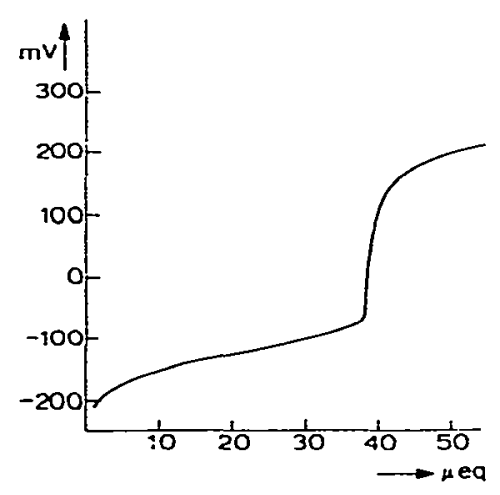

Fig. 4. Coulometric titration of 1,3-diphenylguanidine in $\mathrm{DMSO}-\mathrm{H}_{2}-0.2 \mathrm{M}$ TEAP.

HCres $+\mathrm{e}^{-} \leftrightharpoons$ Cres $^{-}+\frac{1}{2} \mathrm{H}_{2}$ ^

The gas evolved at the electrode was identified as hydrogen. Other evidence for this reaction was obtained by recording the u.v. spectrum of the medium during base generation; this showed an increasing absorption peak around $325 \mathrm{~nm}$, where sodium $m$-cresolate also has an absorption peak.

The results of the coulometric titration of $20-50 \mu \mathrm{eq}$ of some acids in this system are given in Table 5 . The use of $0.1 \mathrm{M}$ cresol in the medium restricts the method to the titration of acids with $p \mathrm{~K}_{\mathrm{a}}$ (DMSO) values below 7, because of the acidity of the cresol.

When a platinized platinum gauze is used as the working electrode, direct internal generation of base is possible from the DMSO-0.2 M TEAP system. Table 6 shows the results for the coulometric titration of 20-150 $\mu$ eq of some acids with this electrode. A typical curve for such a titration is given in Fig. 5. 
TABLE 5.

Coulometric titration of some acids in DMSO-0.3 M TEAP-0.1 M m-cresol with a bright platinum working electrode and a current of $1 \mathrm{~mA}$

\begin{tabular}{lccc}
\hline Compound & $\begin{array}{l}\text { Current } \\
\text { effic. (\%) }\end{array}$ & $\begin{array}{l}\text { No. of } \\
\text { detns. }\end{array}$ & $\begin{array}{l}\text { s } \\
(\%)\end{array}$ \\
\hline Picric acid & 99.9 & 10 & 0.6 \\
2,4-Dinitrobenzenesulfonic acid & 100.1 & 10 & 0.3 \\
2,6-Dinitrophenol & 99.8 & 10 & 0.3 \\
Salicylic acid & 99.8 & 6 & 0.9 \\
\hline
\end{tabular}

TABLE 6

Coulometric titration of some acids in DMSO-0.2 M TEAP with a platinized platinum gauze $\left(4 \mathrm{~cm}^{2}\right)$ working electrode and a current of $3 \mathrm{~mA}$

\begin{tabular}{lcll}
\hline Compound & $\begin{array}{l}\text { Current } \\
\text { effic. (\%) }\end{array}$ & $\begin{array}{l}\text { No. of } \\
\text { detns. }\end{array}$ & $\begin{array}{l}s \\
(\%)\end{array}$ \\
\hline Benzoic acid & 100.2 & 6 & 0.6 \\
2,4-Dinitrobenzenesulfonic acid & 100.0 & 5 & 0.2 \\
Salicylic acid & 99.9 & 5 & 0.6 \\
m-Cresol & 99.4 & 3 & 0.7 \\
2,4-Dinitrophenol & 100.2 & 5 & 0.4 \\
2-Nitrophenol & 100.2 & 3 & 0.2 \\
Perchloric acid & 100.3 & 4 & 0.1 \\
\hline
\end{tabular}

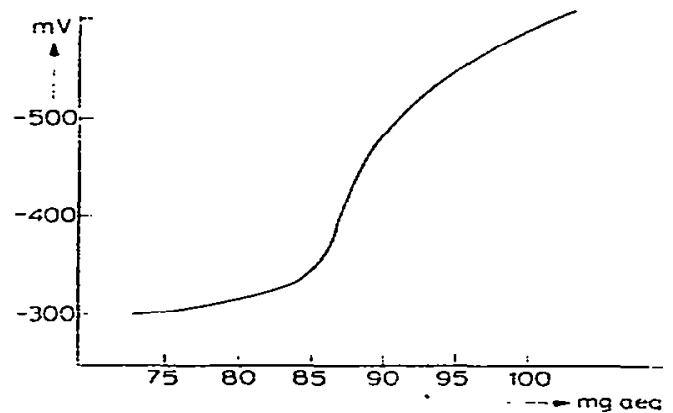

Fig. 5. Coulometric titration of benzoic acid in DMSO-0.2 M TEAP.

The titration of some alcohols like glycerol and t-butanol was also attempted, but no inflection points appeared in the titration curves.

\section{DISCUSSION}

When hydrogen gas is used as the source for protons, the coulometric titration of bases can be carried out successfully in the solvent DMSO. 
The simple mechanism

$$
\begin{aligned}
& \mathrm{H}_{2} \stackrel{\mathrm{Pt}}{\longrightarrow} 2 \mathrm{H}(\mathrm{Pt}) \\
& \mathrm{H}(\mathrm{Pt}) \longrightarrow \mathrm{H}^{+}+\mathrm{Pt}(\mathrm{e})
\end{aligned}
$$

is in accordance with the Tafel slope of $116 \mathrm{mV}$ found for the oxidation of hydrogen on platinum in DMSO, if reaction (2) is rate-determining.

In considering the cause of the passivity region of the hydrogen oxidation on platinum, two observations are important. First, it is noteworthy that hydroquinone can be oxidized without hindrance in the hydrogen passivity region; this excludes the presence of an oxide layer on the platinum surface [9] as the cause of passivity. Secondly, the start of the passivity region is shifted to considerably more negative potentials if tetrabutylammonium nitrate is used as the supporting electrolyte, whereas for tetrabutylamnonium perchlorate the current-voltage curve is practically the same as for tetraethylammonium perchlorate. It is therefore very likely that the passive phenomenon in the electrochemical hydrogen oxidation is caused by adsorption of anions at the platinum surface. This has also been suggested by Schuldiner [10] for the oxidation of hydrogen in some aqueous solutions.

The experiments do not provide much evidence regarding the nature of the electrode reaction during the titration of acids. The evolution of hydrogen gas can be explained if the electrode reaction is assumed to be:

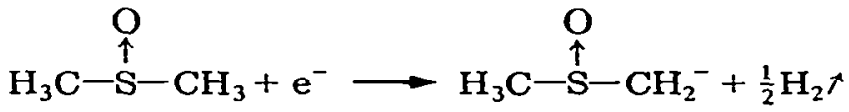

This is in accordance with the negative results for the titration of hydroxy compounds such as t-butanol if the tetraethylammonium ion lowers the reactivity of the dimsyl ion in the same way as cesium and potassium ions [3].

The author wishes to thank Mrs. B. Verbeeten-van Hettema for preparing the manuscript.

\section{REFERENCES}

1 I. M. Kolthoff and T. B. Reddy, Inorg. Chem., I (1962) 189.

2 R. Morales, Anal. Chim. Acta, 48 (1969) 309.

3 L. K. Hiller, Anal. Chem., 42 (1970) 30.

4 C. Lemahieu-Hodé, B. Résibois and C. Lemahieu, Analusis, 1 (1972) 23.

5 R. L. Benoit and C. Buisson, Electrochim. Acta, 18 (1973) 105.

6 V. J. Vajgand and R. Mihajlovié, Talanta, 16 (1969) 1311.

7 M. Bos and E. A. M. F. Dahmen, Anal. Chim. Acta, 72 (1974) 345.

8 T. C. Franklin and H. Kagawa, Electrochim. Acta, 17 (1972) 1213.

9 M. Breiter and C. A. Knorr, Z. Elektrochem., 59 (1955) 153.

10 S. Schuldiner, J. Electrochem. Soc., 115 (1968) 362.

11 S. Schuldiner, J. Electrochem. Soc., 116 (1969) 767. 